\title{
Crise da água na região metropolitana de São Paulo: injustiça ambiental, privatização e mercantilização de um bem comum
}

\author{
Ana Paula Fracalanza \\ EACH-USP \\ Thais Magalhães Freire \\ EACH-USP \\ p. $464-478$
}

revista

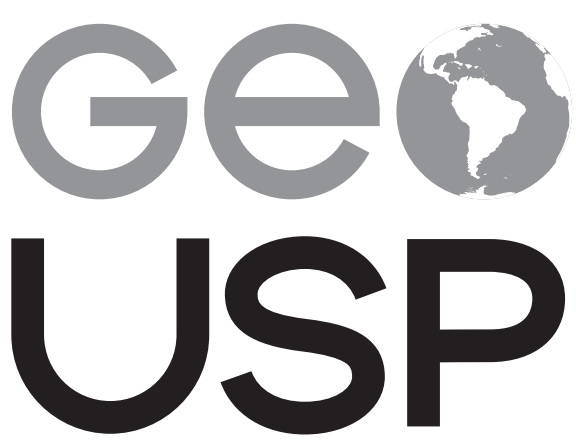

espaço e tempo

Volume $19 \bullet n^{\circ} 3$ (2015)
Como citar este artigo:

FRACALANZA, A. P.; FREIRE, T. M. Crise da água na Região Metropolitana de São Paulo: injustiça ambiental, privatização e mercantilização de um bem comum. Geousp - Espaço e Tempo (Online), v. 19, n. 3, p. 464-478, mês. 2016. ISSN 2179-0892.

Disponível em: URL: http://www.revistas.usp.br/ geousp/article/view/103064. DOI: http://dx.doi. org/10.11606/issn.2179-0892.geousp.2015.103064.

\section{(c) ${ }_{\mathrm{BY}}(\mathrm{BC}$}

Este artigo está licenciado sob a Creative Commons Attribution 4.0 License. 


\title{
Crise da água na região metropolitana de São Paulo: injustiça ambiental, privatização e mercantilização de um bem comum
}

\section{Resumo}

Este artigo discute a água como bem comum, direito de todos, e a injustiça ambiental envolvida na crise hídrica na Região Metropolitana de São Paulo. Conclui-se pela injustiça ambiental no caso dessa crise porque é a população de mais baixa renda e mais vulnerável econômica e ambientalmente que tem mais dificuldade de acesso à água em quantidade e qualidade. Por outro lado, a população de mais alta renda tem maiores possibilidades de obtenção da água, de maneira privada. Isso contribui para acentuar o crescimento da apropriação privada da água como mercadoria, acentuando a privatização e a mercantilização de um bem comum.

Palavras-chave: Água. Bem comum. Bem privado. Injustiça ambiental. Região Metropolitana de São Paulo.

\section{Water crisis in São Paulo metropolitan area: the environmental injustice, the privatization and the commodification of a common good $\backslash$}

\begin{abstract}
This article aims to discuss the water as a common good, right for all, and the environmental injustice involved in water crisis in São Paulo Metropolitan Area. The results confirmed the existence of environmental injustice in the case of the water crisis in São Paulo Metropolitan Area. The mosteconomic and environmental vulnerable population presents greater difficulties of access to water in quantity and quality for survival. On the other hand, the population with the highest income have greater possibilities of obtaining water privately. This helps to enhance the growth of the private appropriation of water as a commodity, emphasizing the privatization and the commodification of a common good.
\end{abstract}

Keywords: Water. Private goods. Common resources. Environmental injustice. São Paulo Metropolitan Area. 


\section{Introdução}

Na legislação brasileira, a água é considerada um bem de domínio público, sendo direito de todos. Neste caso, todos devem preservá-la e, sendo um bem necessário e essencial à vida, todos têm direito a seu uso. Além desse fundamento, a Política Nacional de Recursos Hídricos, instituída pela Lei Nacional n. 9.433/1997, indica que a água é um recurso natural limitado, dotado de valor econômico e que, entre os usos prioritários dos recursos hídricos, está o abastecimento humano.

Esses fundamentos apontam para alguns aspectos que vêm sendo discutidos atualmente quando se considera a gestão das águas na Região Metropolitana de São Paulo (RMSP): a escassez hídrica, o valor econômico da água e o abastecimento humano.

Uma questão importante ao se discutir as possibilidades de uso da água para uma população é pensar no território, na água territorializada em bacias hidrográficas e nos sistemas de objetos e sistemas de ações que resultam no espaço transformado que permite o uso da água por essa população (Santos, 1996; Fracalanza, 2002).

No Brasil, com o desenvolvimento capitalista no século XX houve processos de acumulação extensiva e intensiva relacionadas ao uso dos recursos hídricos para realização de atividades humanas (Acselrad; Mello; Bezerra, 2009). No caso da acumulação extensiva, territórios foram sendo ocupados por grandes empreendimentos, resultando em desmatamentos de margens de rios, em assoreamento de corpos d'água e em inundação de grandes áreas pela construção de grandes barragens. Quanto à acumulação intensiva, os ritmos acelerados de produção chocaram-se com os ritmos lentos de regeneração dos meios biofísicos, gerando, entre outros, acumulação de metais pesados em rios e lagos (Acselrad; Mello; Bezerra, 2009).

Nesses casos, a produção de efeitos negativos ao ambiente, chamada pelos economistas de externalidades ambientais negativas, resulta em danos não incorporados ao processo produtivo e ao capital. Outrossim, resulta em processos que prejudicam a qualidade de vida de populações, de forma direta e indireta - direta, para aqueles que têm que se deslocar de seu território, por exemplo, pela construção de barragens; indiretas, para aquelas populações que são mais atingidas pelos danos ao ambiente, ou ainda pelas externalidades ambientais negativas.

No caso da crise de abastecimento de água para parte da população da RMSP, há uma série de questões fundamentais a se considerar, que podem ser refletidas a partir dos conceitos de injustiça ambiental, de governança ambiental e de água como mercadoria: qual a relação entre a crise hídrica e a injustiça ambiental? De que forma o não cumprimento de ações previstas na gestão do sistema pelos operadores do mesmo intensifica a injustiça ambiental e contribui para a mercantilização do recurso? Essas questões serão discutidas neste artigo.

\section{Problemas na gestão do Sistema Cantareira}

Atualmente, a RMSP é formada por 39 municípios, dos quais 34 pertencem à bacia hidrográfica do Alto Tietê,' bacia essa que ocupa área de $5.985 \mathrm{~km}^{2}$. O polo central dessa região, a cidade de São Paulo, apresenta-se hoje como uma megacidade, contando com quase 11 milhões de habitantes.

1 Dos 39 municípios dessa região, só não pertencem à bacia hidrográfica ao Alto Tietê: Guararema, Juquitiba, Santa Isabel, São Lourenço da Serra e Vargem Grande Paulista. 
A partir de 2014, tem sido observada uma crise hídrica para abastecimento da RMSP.É importante considerar que a RMSP consome mais água do que produz: o consumo para abastecimento público é da ordem de $68,2 \mathrm{~m}^{3} / \mathrm{s}$, sendo que, historicamente, $31 \mathrm{~m}^{3} / \mathrm{s}$ de água têm sido importados da bacia hidrográfica dos rios Piracicaba, Capivari e Jundiaí, constituindo o Sistema Cantareira (ANA, [s.d.]). A bacia hidrográfica do rio Piracicaba está ligada ao Sistema Cantareira por barragens de regularização operadas pela Companhia de Saneamento Básico do Estado de São Paulo (Sabesp) e construídas a partir de meados da década de 1960 nos rios Atibaia e Jaguari, afluentes do rio Piracicaba (Lopes, 2003, p. 123-125).

\section{Figura 1 - Sistema Cantareira}

\section{Sistema Cantareira}

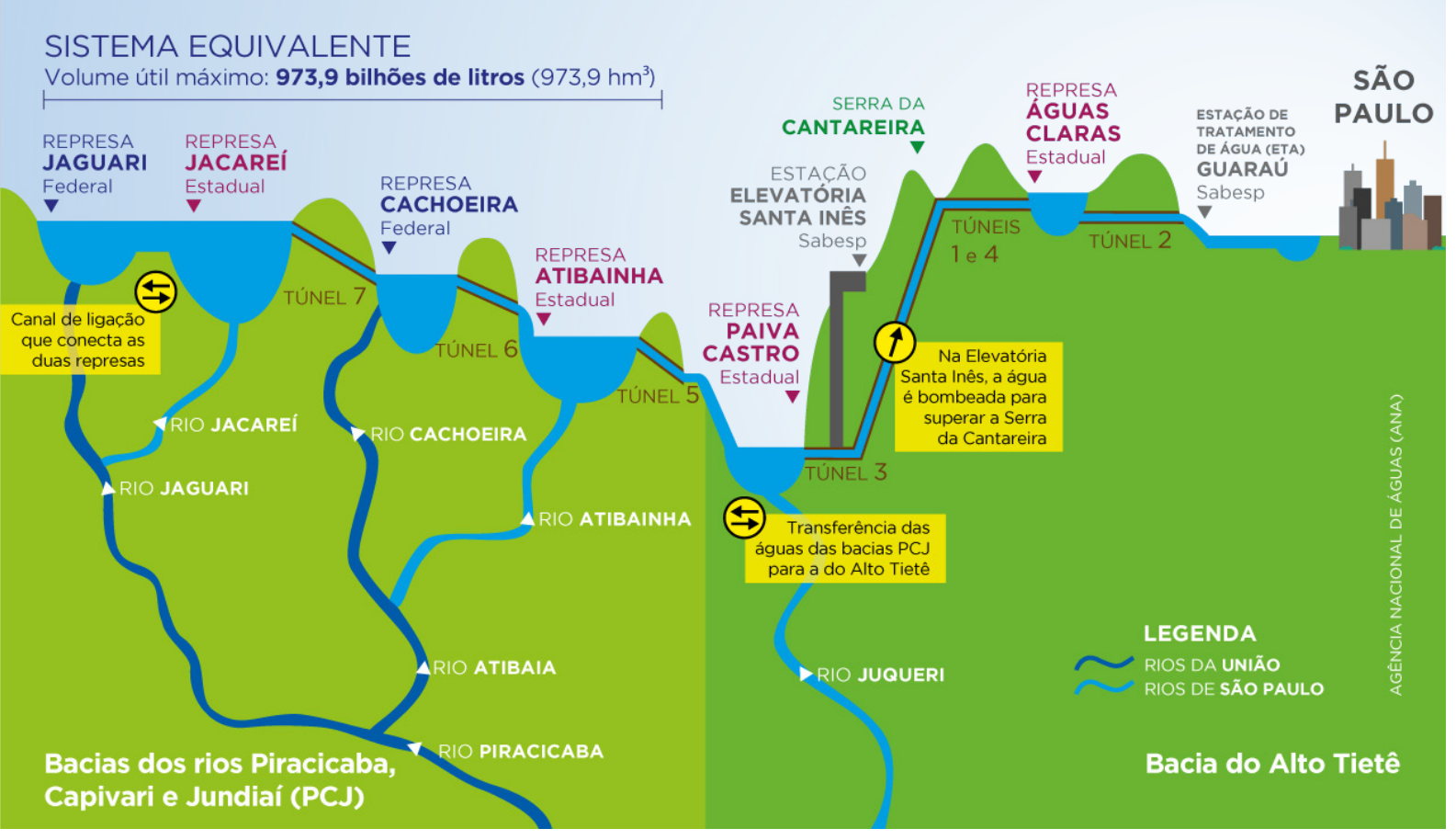

fonte: ANA (2015).

Por sua vez, as bacias hidrográficas dos rios Piracicaba, Capivari e Jundiaí ocupam área de 58 municípios, entre eles municípios da Região Metropolitana de Campinas (RMC). A RMC, criada em 2000, compreende 19 municípios, ${ }^{2}$ com uma população total de cerca de 2,33 milhões de habitantes. A RMC, assim como os municípios de Jundiaí, Campo Limpo, Várzea Paulista, Piracicaba, Limeira, Rio Claro e Bragança Paulista são afetados pelo Sistema Cantareira, já que o rio Piracicaba, juntamente com os rios Capivari e Jundiaí são rios que compõem a bacia hidrográfica responsável pelo abastecimento da região. Assim, sendo um volume de até $31 \mathrm{~m}^{3} / \mathrm{s}$ retirados da bacia hidrográfica do rio Piracicaba para abastecimento da RMSP, diminui o volume de água afluente às cidades abastecidas pelos rios Piracicaba, Capivari e Jundiaí.

2 Os 19 municípios que compõem a RMC são: Americana, Artur Nogueira, Campinas, Cosmópolis, Engenheiro Coelho, Holambra, Hortolândia, Indaiatuba, Itatiba, Jaguariúna, Monte Mor, Nova Odessa, Paulínia, Pedreira, Santa Bárbara d'Oeste, Santo Antônio de Posse, Sumaré, Valinhos e Vinhedo. 
Frente ao quadro de escassez hídrica que vem se apresentando na RMSP e na RMC, tem havido diminuição do uso das águas do Sistema Cantareira, já que esse sistema tem sua capacidade de fornecimento de água diminuída por uma crise hídrica e de gestão. Esta situação vem impactando a oferta de água nas duas regiões acima citadas, e dificultando soluções de abastecimento público.

Sistema Cantareira vem sendo usado para o abastecimento público da RMSP desde 1974. A primeira outorga de direito de uso do Sistema Cantareira foi concedida pelo Ministério de Minas e Energia (MME) de modo centralizado à Sabesp, em agosto de 1974, pela Portaria n. 750. A partir de então, a Sabesp tornou-se responsável pela utilização dos recursos hídricos do Sistema Cantareira com vazão máxima de $33 \mathrm{~m}^{3} / \mathrm{s}$ para o abastecimento público da RMSP por 30 anos.

Contudo, com a transposição das águas do Sistema Cantareira para a RMSP com a vazão máxima estabelecida em 33 m³/s houve uma redução drástica da vazão liberada para o rio Piracicaba, logo as bacias dos rios Piracicaba, Capivari e Jundiaí (PCJ) tornaram-se as mais prejudicadas com a retirada da água.

Em 2003, ao se aproximar o fim do primeiro período de outorga das águas do Sistema Cantareira para a Sabesp, começou-se a discutir sua renovação. No primeiro semestre de 2004 houve diversas campanhas, debates e divulgações de dados na região das bacias PCJ e como a ideia de gestão descentralizada era central, houve uma série de manifestações por parte da sociedade civil que reivindicavam uma gestão compartilhada. Em agosto de 2004, a outorga do Sistema Cantareira foi renovada, e a gestão passou de centralizada a compartilhada entre a região do Alto Tietê e do PCJ. Pela Portaria Daee n. 1.213 (São Paulo, 2004), que instituiu a renovação da outorga por mais 10 anos, a região das bacias PCJ passou a contar com a vazão mínima estabelecida. Entre as garantias estabelecidas pela nova outorga, destacam-se a definição de uma vazão máxima de água a ser retirada da porção do sistema inserida na bacia do Piracicaba, a definição de metas de tratamento de esgotos nos municípios do PCJ e um banco de águas criado para armazenar o volume não utilizado no período de chuvas para usá-la em tempos de estiagem (Whately; Cunha, 2007).

documento de renovação da outorga havia sido discutido por membros de órgãos, instituições e empresas governamentais, e também não governamentais, além de consórcio e comitês de bacias hidrográficas envolvendo representantes públicos, privados e da sociedade civil. A partir de então, percebe-se uma modificação no modelo de gestão dos recursos hídricos com a inclusão de novos atores que passaram a fazer parte da gestão da água (Fracalanza; Eça; Raimundo, 2013).

Ao entrar em vigor a nova outorga, a Sabesp, como órgão outorgado, comprometeu-se a atingir as metas para tratamento de esgotos urbanos, controle de perdas físicas através das redes de abastecimento e medidas para a recarga do lençol freático. $\bigcirc$ compromisso da Sabesp foi firmado perante um Termo de Compromisso, que se não fosse cumprido poderia acarretar na não renovação da nova outorga em 2014 (Cobrape, 2010).

Entre as condicionantes impostas para a concessão da renovação da outorga, recomendava-se que a vazão máxima transferida da bacia do Piracicaba para a RMSP fosse de até $31 \mathrm{~m}^{3} / \mathrm{s}$, e que as vazões mínimas liberadas para a bacia do rio Piracicaba aumentassem progressivamente de $4 \mathrm{~m}^{3} / \mathrm{s}$ até $7 \mathrm{~m}^{3} / \mathrm{s}$. A Portaria Daee n. 1.213 (São Paulo, 2004) também 
decretou que a operação do Sistema Cantareira deveria obedecer a um limite de vazão de retirada baseado na análise das curvas de aversão ao risco (CAR), as quais garantiriam uma quantidade de vazão de retirada segura, visando a proteção do sistema e evitando seu colapso. De acordo com a Resolução Conjunta ANA/Daee n. 428 (ANA; Daee, 2004), as CAR devem estabelecer limites de níveis de armazenamento mensalmente com bases no volume útil, tornando-se, portanto, referência para vazões de retirada seguras do Sistema Equivalente, a fim de que essas não comprometam o abastecimento pelo Sistema.

A importância do Sistema Cantareira advém não somente do fato de esse ser o principal sistema produtor de água para a RMSP, mas também por representar os desafios e problemas envolvidos na gestão dos recursos hídricos. Além dos conflitos associados à quantidade e qualidade da água, esse sistema envolve conjuntamente a bacia hidrográfica do Alto Tietê e as bacias hidrográficas dos rios Piracicaba, Capivari e Jundiaí.

Maior metrópole brasileira, a RMSP vive hoje uma grave situação de garantia de água em quantidade e qualidade para abastecer sua população. Isso se dá pela dependência da água do Sistema Cantareira para esse abastecimento, água essa oriunda de uma bacia hidrográfica que se encontra em território a noroeste da RMSP. Entre os demais mananciais que abastecem a RMSP, os principais são a represa Billings, a bacia do Guarapiranga e as cabeceiras do rio Tietê, que sofrem com o intenso processo de ocupação em suas margens ao longo dos anos. Logo, em meio a essa breve análise, verifica-se que a região necessita importar água e investir em sistemas de tratamento avançados para tratar água de péssima qualidade e posteriormente utilizá-la para o abastecimento, ao invés de priorizar a manutenção da qualidade de seus mananciais (Borelli, 2011).

Em virtude da crise hídrica que se instalou no verão de 2013-2014, o prazo de vigência da outorga de direito de uso de recursos hídricos do Sistema Cantareira concedido à Sabesp, previsto para agosto de 2014, foi prorrogado até 31 de outubro de 2015, por meio da Resolução Conjunta ANA/Daee n. 910 (ANA; Daee, 2014a).

Cabe observar que, segundo o documento de solicitação de renovação da outorga do Sistema Cantareira pela Sabesp para 2014.

O Sistema Cantareira é imprescindível para o abastecimento público de cerca de 9 milhões de habitantes da Região Metropolitana de São Paulo (RMSP), e também de relevante importância para a regularização dos volumes de água demandados na Região Metropolitana de Campinas (RMC) (São Paulo, 2013, p. 1).

Em função da crise hídrica, e da falta de água no Sistema Cantareira, a nova outorga para o uso das águas do Sistema Cantareira vem sendo discutida e parte da população das regiões metropolitanas de São Paulo e Campinas não estão tendo acesso regular a água. Mas onde começou a crise? Como vinha sendo feita a gestão do Sistema Cantareira? Essas questões serão consideradas a seguir.

\section{Gestão da água na crise hídrica}

A crise hídrica que envolve a RMSP faz com que a gestão da água para abastecimento de sua população enfrente uma série de desafios envolvendo diferentes interesses. 
Em fevereiro de 2014, a Agência Nacional de Águas (ANA) e o Departamento de Águas e Energia Elétrica (Daee) comunicaram conjuntamente a necessidade da criação de uma administração diferenciada do armazenamento do Sistema Cantareira, procurando aperfeiçoar o uso dos recursos hídricos disponíveis e objetivando minimizar eventuais danos aos usuários dependentes desse sistema (ANA; Daee, 2014b). Assim, para a gestão especial do Sistema Cantareira no período de escassez de água, instituiu-se o Grupo Técnico de Assessoramento (GTAG-Cantareira), constituído por um representante da ANA, um do Daee, responsável pela secretaria do Grupo, um do Comitê das Bacias Hidrográficas dos rios Piracicaba, Capivari e Jundiaí (CBH-PCJ), um do Comitê da Bacia Hidrográfica do Alto Tietê (CBH-AT) e um da Sabesp.

De acordo com a Resolução Conjunta ANA/Daee n. 120 (ANA; Daee, 2014b), entre as competências do GTAG-Cantareira, destacam-se a assessoria aos órgãos outorgantes nas decisões quanto à gestão do Sistema Cantareira, o acompanhamento diário dos dados dos reservatórios do Sistema Cantareira e a expedição semanal de relatórios avaliando a situação dos reservatórios e recomendando a vazão média a ser observada nos dias seguintes. Além disso, o GTAG-Cantareira recomenda eventuais medidas de restrição ou suspensão do abastecimento de água aos usuários da RMSP e das bacias dos rios Piracicaba, Capivari e Jundiaí sob influência do Sistema Cantareira (ANA; Daee, 2014b).

Em virtude das decisões que foram tomadas pelos órgãos gestores de forma conjunta e pelas captações retiradas pela Sabesp, os Ministérios Públicos (MP) Federal e do Estado de São Paulo entraram com uma ação civil pública ambiental em 6 de outubro de 2014, para restringir a retirada de água do Sistema Cantareira pela Sabesp.

No documento apresentado pelos promotores, o poder público, baseado em preceitos das legislações, sobretudo da Política Nacional dos Recursos Hídricos (Lei Nacional n. 9.433/97), vem discutindo questões relacionadas à gestão do Sistema Cantareira.

Uma delas diz respeito ao uso das CAR. De acordo com a Nota Técnica Conjunta ANA/Daee n. 428 (ANA; Daee, 2004), que trata dos "subsídios para a análise do pedido de outorga do Sistema Cantareira e para definição das condições de operação dos seus reservatórios", a alocação de água no Sistema Cantareira deve ser baseada conforme as CAR para o Sistema Equivalente formado pelos reservatórios Jaguari-Jacareí, Cachoeira e Atibainha.

O estudo técnico apresenta premissas para a adoção das CAR para o Sistema Equivalente, entre as quais destaca-se a importância de se manter os níveis mínimos de segurança, ou seja, um volume estratégico mínimo, dada a importância do Sistema Cantareira para o abastecimento de grande parte da RMSP e da bacia do rio Piracicaba. No entanto, segundo crítica dos MP Federal e do Estado de São Paulo feita na ação civil pública ambiental, a Sabesp, como órgão responsável pela outorga do Sistema Cantareira, não teria respeitado as Curvas de Aversão ao Risco, o que teria agravado a situação de escassez dos reservatórios do Cantareira.

Ainda se tratando da outorga do Sistema Cantareira e dos deveres dos atores envolvidos na gestão, a Portaria Daee n. 1.213 (São Paulo, 2004) previa que a Sabesp deveria apresentar, no prazo máximo de 30 meses a partir da renovação da outorga, estudos e projetos que viabilizassem a redução da dependência do Sistema Cantareira, devendo considerar os Planos de Bacias dos Comitês PCJ e AT (São Paulo, 2004). 
De acordo com o relatório sobre os Dados de Referência Acerca da Outorga do Sistema Cantareira (ANA; Daee, 2013), a Sabesp chegou a apresentar em 2006 o Plano Diretor de Abastecimento de Água da RMSP (PDAA), que continha projetos para expansão dos sistemas já utilizados, além da incorporação de novos mananciais.

Entretanto, o governo do estado de São Paulo alegou que o PDAA não atendia às condicionantes do que era previsto na Portaria Daee n. 1.213 (São Paulo, 2004). Mediante a necessidade de novos estudos, foi editado o Decreto Estadual n. 52.748, de 26 de fevereiro de 2008, que criou o Grupo de Trabalho responsável por propor alternativas de aproveitamento dos recursos hídricos da Macrometrópole de São Paulo. Esse Decreto previu a compatibilização das propostas apresentadas pelo Grupo de Trabalho com os planos de recursos hídricos já existentes por meios da Lei Estadual n. 7.663/1991 e da Lei Federal n. 9.433/1997 (São Paulo, 2008).

A crítica dos Ministérios Públicos Federal e do Estado de São Paulo à gestão do Sistema Cantareira baseia-se na falta de decisão dos órgãos gestores diante da crise que já se anunciava.

Também de acordo com a ação civil pública ambiental, os estudos hidrológicos comprovavam a redução das precipitações no estado de São Paulo ao longo dos anos, entretanto, indica-se que nenhuma medida havia sido tomada com relação à diminuição da vazão de retirada do Sistema Cantareira por parte dos órgãos gestores (ANA-Daee) ou pela operadora do sistema produtor (Sabesp), muito menos à implantação de um sistema de rodízio para prevenir a escassez hídrica (Ministério Público Federal; Ministério Público do Estado de São Paulo, 2014).

Um estudo técnico realizado pelo Consórcio PCJ em parceria com a Universidade Estadual de Campinas (Unicamp) em dezembro de 2013, observava a necessidade de se iniciar um programa de estímulo à racionalização do uso da água, a fim de que o Sistema Cantareira fosse poupado. De acordo com o estudo técnico, a redução do índice pluviométrico comprometeu as vazões dos rios e a capacidade dos reservatórios do Sistema Cantareira, comprovando, portanto, "a necessidade de início imediato de ações de racionalização do consumo de água por parte dos serviços de água das Bacias PCJ" (Consórcio PCJ, 2013).

$\bigcirc$ que se nota a partir dos das discussões e dos posicionamentos dos atores sociais e agentes governamentais acima expostos é um conflito frente a uma situação de escassez hídrica. $O$ conflito ocorre no campo do que deveria ter sido feito para evitar ou minimizar a crise hídrica, na gestão da crise, e nos danos que vêm sendo provocados pela mesma. $\bigcirc$ conflito ocorre também quanto a um posicionamento claro sobre a adoção do racionamento ou de um sistema de rodízio de água.

No entanto, não foi o que aconteceu. De fato, a crise somente foi anunciada em princípios de 2014. Mas foi anunciada de forma lenta. Lenta e pouco transparente. Anuncia-se e deixa-se de falar nela. Pouco se sabe sobre como a população está sendo atingida pela crise, mas sabe-se que parte da população está tendo dificuldade de acesso à água. Segundo Barbosa (2014, p. 60): Apesar de o governo negar a ocorrência de racionamento, o Idec diz ter recebido 618 relatos de falta de água na capital paulista e na Grande São Paulo, entre os dias 25 de junho e 26 de setembro [2014], sendo que 72\% reclamaram de pelo menos uma interrupção todos os dias. A Sabesp atribui as queixas a eventuais interrupções para manutenção da rede e diz que o número de reclamações é uma amostragem muito pequena comparado ao universo de clientes que atende. 
Apesar de negar o racionamento, a concessionária admite que realiza em algumas regiões a redução da pressão noturna de água, prática que, segunda a empresa, objetiva diminuir perdas de água por vazamento na rede de distribuição.

Nesse caso, além da questão da crise hídrica, há uma crise de governança da água na RMSP. E, pela crise de governança, acentua-se a crise de abastecimento da população que vive na RMSP. Quem sofre falta de água com a crise hídrica? A falta de água representa uma injustiça ambiental para parte da população da RMSP? Essas questões serão consideradas a seguir.

\section{Crise hídrica como sinônimo de desigualdade no acesso à água}

A diferença no acesso à água por parte da população pode ser considerada como caso de injustiça ambiental, quando grupos de população socioeconomicamente excluídos e de mais baixa renda sofrem problemas ambientais decorrentes de água em piores condições de qualidade, ou ainda em quantidade menor, do que aqueles que mais contribuem para o consumo desse bem comum.

A necessidade de compartilhar a água entre todos, além de vital, remete ao conceito de sustentabilidade, já que considera aspectos de justiça ambiental e social. Nesse caso, tratar-se-ia de melhor distribuir a água entre as gerações atuais, ou seja, da questão intrageracional do desenvolvimento sustentável. Assim, coloca-se a importância de disponibilizar água para populações que têm dificuldade de obtê-la em padrões de qualidade e quantidade suficientes para atender suas necessidades.

Assim, cabe observar que, em situações de escassez, é fundamental que as populações sejam orientadas e consideradas igualmente de modo que não sejam prejudicadas em seu acesso à água, de modo a não se estabelecerem conflitos entre os usos da água (por exemplo, industrial e abastecimento doméstico) e de modo a haver uma distribuição mais igualitária da água para populações de modo amplo, não prejudicando o acesso à água por populações de baixa renda.

Nesse caso, o conceito de governança, mais que o conceito de gestão pode levar em consideração aspectos que envolvem os conflitos: mais do que tentativas de eliminá-los, com a governança trata-se da busca de administrar os conflitos, de acordo com um projeto coletivo (Diniz, 1999, p. 197).

No caso da água, considera-se que é possível administrar os conflitos pelos usos da água, mas não se pode eliminar os conflitos. De fato, sua administração poderia estar relacionada a um projeto comum de busca por qualidade adequada da água e por quantidade suficiente para os múltiplos usos que são feitos da água. Mas, como se trata de um recurso escasso e desigualmente distribuído, os conflitos perpetuam-se e alteram-se no tempo e no espaço, sendo administrados em função das demandas dos atores sociais e das necessidades coletivas relacionadas a um bem essencial à vida. Nesse sentido, os conflitos refletem as desigualdades sociais, de modo que alguns usos acabam prevalecendo sobre outros usos (Fracalanza, 2002).

A consideração de conflitos a partir da existência de desigualdades está presente na definição de governança apresentada por Jacobi (2007): 
Adota-se a noção de governança como poder social que media as relações entre Estado e sociedade civil como espaço de construção de alianças e cooperação. Mas também permeado por conflitos que decorrem do impacto das assimetrias sociais e seus impactos no meio ambiente e das formas de resistência, organização e participação dos diversos atores envolvidos (Jacobi, 2007, p. 2).

Nessa definição, além de aspectos sociais da gestão da água, relacionados a mecanismos de participação e distribuição, são explicitadas questões políticas, envolvendo poder e conflitos. Além disso, na definição de governança é importante levar em conta um campo de análise mais amplo, que inclui novos atores sociais e aspectos de participação (Ribeiro, 2009, 2012).

Quando entram em discussão os conflitos pelos usos da água, ao considerar as relações entre sociedade e natureza e sua influência nas configurações espaciais, torna-se importante observar como se dá a apropriação e transformação do espaço a partir de dimensões sociais e políticas (Pace; Barsky, 2012; Guillén, 2007; Ribeiro, 2008, 2013). Nesse sentido, é importante ressaltar que existem conflitos relativos à gestão da água que não têm relação com quem faz essa gestão a partir de que território. Mais do que isso, esses conflitos dizem respeito a quem se destina a água, ou seja, a quem se apropria dela. Nesse caso, trata-se de conflitos sociais por acesso, distribuição e apropriação, ou pelo uso dos chamados recursos hídricos de uma forma mais igualitária pelas populações de baixa renda.

Reclamar acesso igualitário de água poderia configurar a busca de justiça ambiental quanto à apropriação dos recursos hídricos. Conforme Bullard (2004, p. 46), justiça ambiental significa: "tratamento justo e o significativo envolvimento de todas as pessoas, independentemente de raça, cor, nacionalidade ou rendimento, no desenvolvimento, implementação e cumprimento das leis, regulamentações e políticas públicas ambientais".

No entanto, em territórios nos quais não há cobertura de serviços de saneamento básico para toda a população, também não há tratamento justo quanto à questão do oferecimento de serviços relacionados a saneamento básico para a população. Ao contrário, há uma tendência da população de baixa renda a habitar territórios sujeitos a maiores riscos em relação a problemas ambientais, de modo geral, e a problemas relacionados à falta de saneamento adequado, de modo particular, tais como em áreas: sujeitas a inundações; com condições inadequadas de saneamento ambiental; próximas a lixões; com riscos de desabamento associados a processos erosivos.

Nesse sentido, a injustiça ambiental encontra-se no fato de a população que menos contribui com o agravamento dos problemas ambientais decorrentes dos processos de industrialização e de consumo de bens e serviços, ser a população que mais sofre com os problemas ambientais decorrentes dos mesmos processos de industrialização e consumo.

No caso da água no Brasil, a Lei Nacional n. 9.433/1997, que institui a Política Nacional de Recursos Hídricos, estabelece como uma de suas diretrizes o uso prioritário dos recursos hídricos, superficiais e subterrâneos, para abastecimento das populações. Assim, para que haja justiça ambiental, há que garantir a toda a população água em quantidade e qualidade adequadas para o abastecimento doméstico. 
No caso atual da crise hídrica, não é o que vem sendo verificado. De fato, as populações mais vulneráveis socioeconomicamente são aquelas que têm tido maiores dificuldades de acesso à água em quantidade e qualidade adequadas à vida. Em quantidade, com a crise hídrica, tem havido falta de água principalmente em regiões periféricas, onde a população tem mais dificuldade de armazenar água, por não ter caixas d'água, por exemplo. E, em qualidade, pelo não abastecimento regular de água, pelos problemas decorrentes da contaminação por encanamentos de esgoto e pelas condições irregulares de armazenamento de água, entre outros aspectos.

Há cinco meses, no auge da crise, o governo paulista anunciou que distribuiria caixas-d'água a moradores da periferia que, sem um reservatório em casa, sofrem mais as consequências do racionamento imposto pelo Estado por meio da técnica de redução de pressão na rede. [...] Com menos pressão, a água é empurrada com menor força nos canos, o que, na prática, deixa com menos água as casas em locais altos e mais distantes das represas de SP. [... . No auge da crise, o governo tucano responsabilizou famílias sem caixa-d'água pelo desabastecimento que ocorre há meses em alguns pontos (Lobel, 2015).

Essas condições de acesso quali-quantitativo à água tendem a ser diferentes quando se consideram os níveis socioeconômicos das populações. Nesse caso, é importante verificar as possibilidades de acesso à água e a questão da água como mercadoria.

\section{Escassez, privatização e injustiça ambiental}

Em situações de escassez hídrica e dadas as desigualdades socioeconômicas da população, as populações com maiores recursos financeiros e mais acesso a infraestrutura sanitária têm melhores condições de obtenção da água: seja dos recursos hídricos disponibilizados pelo governo, seja pela compra da água fornecida por agentes privados.

Na RMSP, no caso da água fornecida pela Sabesp, as melhores condições de acesso à água se dão pela capacidade de pagamento da água, de seu armazenamento (em caixas d'água, por exemplo), e de moradia regularizada e com fornecimento regular de abastecimento de água.

Quanto à água fornecida por agentes privados, a possibilidade de pagamento permite que a população com melhores condições de renda tenha maiores facilidades de acesso aos recursos hídricos em qualidade e quantidade para diferentes usos.

Este é o caso da água envasada. Após seu envase, a água é considerada alimento, sendo sua qualidade controlada pela Agência Nacional de Vigilância Sanitária (Anvisa). Na categoria de água envasada estão a água mineral natural, a água potável de mesa, a água adicionada de sais (Queiroz, 2013). É importante observar que, ao se engarrafar água e vendê-la ao natural ou adicionada de outros compostos, se a transforma em mercadoria, agregando-lhe valor.

No entanto, nem todos podem pagar para ter acesso à água para beber. Além disso, a água envasada não deveria substituir o abastecimento público, já que a água é um bem comum, bem esse necessário à vida humana e dos seres vivos. Nesse sentido, a legislação brasileira, conforme exposto acima, considera a água um bem de domínio público, direito de todos. 
Ainda de acordo com a legislação brasileira, que institui a Política Nacional de Recursos Hídricos, pela Lei Federal n. 9.433/1997, em situações de escassez hídrica, são usos prioritários da água o abastecimento doméstico (populações humanas) e a dessedentação de animais (abastecimento dos animais). Outros usos, como industriais, agrícolas, geração de energia hidrelétrica deixam de ser prioritários.

Contudo, a aplicação da legislação e seu controle esbarram na desigualdade na distribuição de água, em uma sociedade desigual, onde se paga pelo acesso à água, e onde a água, para ser apropriada, deve ser paga para aqueles que a captam, a distribuem, auferem lucratividade e geram valor pelo seu uso.

Muito se discute mundialmente em relação aos conflitos pela água, em relação a sua apropriação desigual (Porto-Gonçalves, 2006; Barlow; Clarke, 2003).

Mas se o uso considerado mais importante e principal da água é para a manutenção da vida dos seres vivos, seria de se esperar que seu uso não refletisse em injustiça ambiental, principalmente em situação em que há acirramento de escassez hídrica.

Todavia, a venda de água envasada vem aumentando com a crise hídrica. Mas se a população tiver que recorrer ao consumo de água envasada para suprir suas necessidades de consumo, pode-se estar caminhando para uma nova forma mercantilização de um bem comum.

Em reportagem do jornal da Folha de S.Paulo, Zafalon (2015, p. 1) observa:

Os que recorrem à água mineral para complementar a necessidade da casa tiveram uma elevação de 19\% nos custos de janeiro do ano passado a abril deste ano [2015]. Nesse mesmo período, a inflação média teve elevação de 10\%. Os dados são da Fipe [Fundação Instituto de Pesquisas Econômicas] e se referem ao município de São Paulo. E água cooperou para essa taxa.

Portanto, enquanto parte da população recorre à água engarrafada como uma opção para abastecimento, outra parte da população vem apresentando dificuldades no acesso à água como bem comum.

De acordo com Barlow (2009), há uma crise mundial da água e o problema é que a conservação da água não dá lucro. Segundo a autora,

[...] é uma grande vantagem para a indústria privada da água que os suprimentos de água doce do mundo estejam sendo poluídos e destruídos. Mesmo que os líderes corporativos individuais não tenham prazer na crise global da água, é exatamente essa crise que está impulsionando os lucros em seu setor (Barlow, 2009, p. 100).

Essa dificuldade e desigualdade no acesso à água, em que a população de mais baixa renda, que menos contribui com o consumo de água, que menos gera lixo é aquela que tem menor acesso ao saneamento básico, seja abastecimento em quantidade e regularidade de água, em coleta de esgotos ou mesmo de lixo, configura uma situação de injustiça ambiental na RMSP.

Desse modo, vê-se uma situação em que o bem comum - a água - distribuído pela empresa de abastecimento público não é uniformemente acessível a toda a população de um território e que sua apropriação desigual incentiva o consumo da mercadoria água das grandes corporações.

No entanto, há um problema no controle da água pelas corporações, segundo Barlow 
(2009, p. 101):

[... ] a água e sua infraestrutura - desde serviços de água potável e concessionárias de saneamento até água engarrafada, tecnologias de limpeza e usinas de dessalinização abastecidas por energia nuclear - fluirão para onde há dinheiro, e não para onde é necessária. Nenhuma corporação está nessa atividade para fornecer água aos pobres. Isso, dizem os líderes corporativos, é função dos governos. As pessoas que não podem pagar não serão servidas.

Esse é um grande risco da crise que ora se apresenta. Todos dependem da água para viver, da água como elemento da natureza. A legislação brasileira considera a água como bem de domínio público, a que todos têm direito. Os governos fazem sua gestão. A boa governança da água considera o abastecimento para toda a população, inclusive a população mais vulnerável dos pontos de vista social e ambiental. Mas, na atual crise hídrica na RMSP, estamos observando uma injustiça ambiental no abastecimento da água, em que a água está apropriada como mercadoria de forma desigual pela população.

\section{Considerações finais}

Neste artigo, discutiu-se a água como bem comum e sua apropriação privada e venda como mercadoria na sociedade atual. $\bigcirc$ debate se concentrou na forma como a crise hídrica na RMSP vem concorrendo para a desigualdade no acesso desse elemento natural fundamental à vida.

Do ponto de vista da governança, a crise hídrica suscitou discussões sobre as instituições envolvidas na gestão do Sistema Cantareira e sobre a prorrogação da discussão da renovação da outorga desse Sistema para a Sabesp. Mas pouco se discutiu sobre que população sofreria cortes no abastecimento de água e os motivos para esses cortes. De fato, os cortes no abastecimento não foram admitidos pelo governo do estado de São Paulo.

Nesse sentido e frente ao quadro apresentado, concluímos pela injustiça ambiental no caso da crise hídrica na RMSP, porque é a população de mais baixa renda e mais vulnerável econômica e ambientalmente que tem maios dificuldade de acesso à água em quantidade e qualidade para sua sobrevivência.

Por fim, mostrou-se que uma alternativa ao abastecimento público de água, ou seja, à água obtida como bem comum, tem sido a compra de água como mercadoria, como é a compra de água envasada. Nesse caso, trata-se da substituição de um bem comum por um bem privado, o que acentua a privatização de um bem a que todos têm direito, a água, considerada pela legislação brasileira direito de todos.

Portanto, a discussão proposta neste artigo diz respeito à governança da água em sentido amplo, pois não considera apenas os atores envolvidos na gestão da água, mas também a população humana que recebe os recursos hídricos pelo uso da água chamado abastecimento de água tratada. Assim, no caso de uma crise de abastecimento de água, ressaltamos a importância de se estabelecer estratégias para a população que mais sofre com o desabastecimento, a fim de não acentuar ainda mais a injustiça ambiental no acesso à água tratada. 


\section{Referências}

ACSELRAD, H.; MELLO, C. C. A.; BEZERRA, G. N. O que é justiça ambiental. Rio de Janeiro: Garamond, 2009.

ANA. AGÊNCIA NACIONAL DE ÁGUAS. Sistema Cantareira, Brasília, DF, 7 out. 2015. Disponível em: <http://www2.ana.gov.br/Paginas/servicos/outorgaefiscalizacao/sistemacantareira.aspx>. Acesso em: 10 dez. 2015.

. Atlas Brasil: abastecimento urbano de água, [s.d.]. Disponível em: <http:// atlas.ana.gov.br/Atlas/forms/analise/RegiaoMetropolitana. aspx?rme=24>. Acesso em: 7 ago. 2015.

; DAEE. DEPARTAMENTO DE ÁGUAS E ENERGIA ELÉTRICA. Resolução Conjunta ANA/Daee n. 910, de 7 de julho de 2014a. Dispõe sobre a prorrogação do prazo de vigência da outorga de direito de uso de recursos hídricos do Sistema Cantareira para a Sabesp - Companhia de Saneamento Básico do Estado de São Paulo. Disponível em: <http://arquivos.ana.gov.br/resolucoes/2014/910-2014.pdf>. Acesso em: 7 dez. 2015.

Resolução Conjunta ANA/Daee n. 120, de 10 de fevereiro de 2014b. Dispõe sobre a criação do grupo técnico de assessoramento para a gestão do Sistema Cantareira no atual período de crise de escassez de chuvas e afluências. Disponível em: <http://www.agenciapcj.org.br/docs/gestao/resolucao-ana-daee-120.pdf>. Acesso em: 7 ago. 2015.

Resolução Conjunta ANA/Daee n. 428, de 4 de agosto de 2004. Dispõe sobre as condições de operação dos reservatórios Jaguari-Jacareí, Cachoeira e Atibainha, localizados na bacia do rio Piracicaba, pertencentes ao Sistema Cantareira. Disponível em: <http://www.comitepcj.sp.gov.br/download/Res ANA-DAEE_428-04.pdf>. Acesso em: 10 dez. 2015.

. Dados de Referência Acerca da Outorga do Sistema Cantareira. Brasília, DF, 16 ago. 2013. Disponível em: <http://audienciapublica.ana.gov.br/arquivos/Aud_001_2014_DadosdeReferenciaAcercadaOutorgadoSistemaCantareira.pdf>. Acesso em: $10 \mathrm{dez} .2015$.

BARBOSA, V. A última gota. São Paulo: Planeta, 2014.

BARLOW, M. Água, pacto azul: a crise global da água e a batalha pelo controle da água potável no mundo. São Paulo: M. Books, 2009.

; CLARKE, T. Ouro azul. São Paulo: M. Books, 2003.

BORELLI, E. Mananciais urbanos e sustentabilidade na Grande São Paulo. In: ENCONTRO NACIONAL DA ANPUR, 14., 2011, Rio de Janeiro. Disponível em: <http://unuhospedagem.com.br/revista/rbeur/index.php/anais/article/viewFile/3700/3625>. Acesso em: 13 out. 2014.

BULLARD, R. Enfrentando o racismo ambiental no século XXI. In: ACSELRAD, H.; HER- 
CULANO, S.; PÁDUA, J. A. Justiça ambiental e cidadania. Rio de Janeiro: Relume Dumará, 2004. p. 41-68.

COBRAPE. COMPANHIA BRASILEIRA DE PROJETOS E EMPREENDIMENTOS. Plano das bacias hidrográficas dos rios Piracicaba, Capivari e Jundiaí 2010-2020. Relatório Final, [200-]. [S.1.]: Agência de Água PCJ, 2010. Disponível em: <http://www. comitepcj.sp.gov.br/download/PB/PCJ_PB-2010-2020_RelatorioFinal.pdf>. Acesso em: 7 ago. 2015.

Plano Diretor de Aproveitamento de Recursos Hídricos para a Macrometrópole Paulista, no estado de São Paulo. Relatório Final, Volume III - Nota Técnica. São Paulo: Daee, 2013.

CONSÓRCIO PCJ. Estudo atenta sobre a necessidade de início imediato de racionalização de água para poupar o Cantareira. Consórcio PCJ, 19 dez. 2013. Disponível em: $<$ http://agua.org.br/estudo-atenta-sobre-a-necessidade-de-inicio-imediato-de-racionalizacao-de-agua-para-poupar-cantareira/> . Acesso em: 8 fev. 2015.

DINIZ, E. Crise, reforma do Estado e governabilidade: Brasil, 1985-1995. Rio de Janeiro: Fundação Getúlio Vargas, 1999.

FRACALANZA, A. P. EÇA, R. F;; RAIMUNDO, S. Renovação da Outorga do Sistema Cantareira (São Paulo-Brasil): gestão compartilhada e perspectivas para 2014. In: RIBEIRO, W. C. (Org.). Conflitos e cooperação pela água na América Latina. São Paulo: Annablume/PPGH, 2013.

Conflitos na apropriação da água na Região Metropolitana de São Pau-

lo. Tese (Doutorado em Geografia) - Faculdade de Ciências e Tecnologia, Universidade Estadual Paulista, Presidente Prudente, 2002.

GUILLÉN, E. A. et al. Per una nova cultura del territori? Mobilizacions i Conflictes Territorials. Barcelona: Icaria, 2007.

JACOBI, P. R. Governança da água no Brasil e os desafios da participação. In: ENCONTRO INTERNACIONAL GOVERNANÇA DA ÁGUA NA AMÉRICA LATINA, 1., 2007, São Paulo. Anais..., São Paulo, 2007.

LOBEL, F. Promessa de caixas d'água para a periferia trava em São Paulo. Folha de S. Paulo, São Paulo, 9 maio 2015.

LOPES, P. D. Bacias dos rios Piracicaba, Capivari e Jundiaí. In: JOHNSSON, R. M. F; LOPES, P. D. (Org.). Projeto Marca d'Água: seguindo as mudanças na gestão das bacias hidrográficas do Brasil. Brasilia: Finatec, 2003.

MINISTÉRIO PÚBLICO FEDERAL; MINISTÉRIO PÚBLICO DO ESTADO DE SÃO PAULO. Ação Civil Pública n. 14.1096.0000006/2013-9. Piracicaba, 30 set. 2014. Disponível em: <http://www.prsp.mpf.mp.br/sala-de-imprensa/noticias_prsp/ ACP\%20-\%20sistema\%20cantareira.pdf>. Acesso em: 7 ago. 2015. 
OCHSENHOFER, K. Gestão das águas no estado de São Paulo: uma análise das renovações da outorga de uso das águas do Sistema Cantareira para a RMSP (2004 e 2015). Monografia (Graduação em Gestão Ambiental) - Escola de Artes, Ciências e Humanidades da Universidade de São Paulo, São Paulo, 2014.

PACE, M.; BARSKY, A. Agua y territorio. Buenos Aires: Fundación CICCUS/Los Polvorines: Universidad Nacional de General Sarmiento, 2012.

PORTO-GONÇALVES, C. W. El agua no se niega a nadie. Polis, Santiago, Chile, v. 5, n. 14, 2006.

QUEIROZ, J. Envase de água: mercantilizando a sede. São Paulo: Annablume/Belo Horizonte: Fapemig, 2013.

RIBEIRO, W. C. (Org.). Conflitos e cooperação pela água na América Latina. São Paulo: Annablume/PPGH, 2013.

. (Org.). Governança da ordem ambiental internacional e inclusão social. São Paulo: Annablume/Procam/IEE, 2012.

(Org.). Governança da água no Brasil: uma visão interdisciplinar. Paulo: Annablume/Fapesp/CNPq, 2009.

Geografia política da água. São Paulo: Annablume, 2008.

SANTOS, M. A natureza do espaço: técnica e tempo, razão e emoção. São Paulo: Hucitec, 1996.

SÃO PAULO. Assembleia Legislativa do Estado de São Paulo. Decreto n. 52.748, de 26 de fevereiro de 2008. Disponível em: <http://www.al.sp.gov.br/norma/?id=76441>. Acesso em: 10 dez. 2015.

SÃO PAULO (Estado). Secretaria de Estado de Energia, Recursos Hídricos e Saneamento. Departamento de Águas e Energia Elétrica. Portaria n. 1.213, de 6 de agosto de 2004. Disponivel em: <http://www.agenciapcj.org.br/docs/gestao/portaria-daee-1213.pdf> . Acesso em: 7 ago. 2015.

SÃO PAULO. Sabesp. Solicitação de Renovação da Outorga pela Sabesp, São Paulo, 2013. Disponível em: <http://arquivos.ana.gov.br/institucional/sof/Renovacao_Outorga/Sabesp-RenovacaodeOutorgadoCantareira.pdf>. Acesso em: 7 ago. 2015.

WHATELY, M.; CUNHA, P. Cantareira 2006: um olhar sobre o maior manancial de água da Região Metropolitana de São Paulo. São Paulo: Instituto Socioambiental, 2007.

ZAFALON, M. Água mineral sobe 19\% para consumidor: inflação é de 10\% em SP. Folha de S.Paulo, São Paulo, 29 abr. 2015. 